\title{
Models for Oxidation Catalyst: Characterization and Reaction at the Atomic Level
}

\author{
H.-J. Freund ${ }^{1}$ \\ Fritz-Haber-Institut der Max-Planck-Gesellschaft, \\ Faradayweg 4-6, D-14195 Berlin, Germany
}

$\underline{\text { Abstract }}$

Three case studies to demonstrate the ability to characterize oxidation model catalysts and reactions of these systems at the atomic level are reviewed. Firstly, results on small $\mathrm{Au}$ aggregates on a clean $\mathrm{MgO}(100)$ surface which are interesting model systems for low temperature oxidation are considered. Secondly oxidative dehydrogenation of methanol on alumina supported Pd is addressed. The problem of oxygen storage in and on the Pd particles is studied for nanoparticles on $\mathrm{Fe}_{3} \mathrm{O}_{4}(111)$. Finally morphology-spectroscopy relations for oxide supported so-called monolayer vanadia catalysts are investigated.

$\underline{\text { Keywords }}$

model catalysts, nanoparticles, molecular beam, Vibrational spectroscopy, structurespectroscopic relations

\section{$\underline{\text { Introduction }}$}

Creating model catalysts has come quite a way over the last decade [1-5]. Nanoparticles have been grown on well defined substrates, i.e. oxide surfaces on bulk single crystals or thin films [6]. Its nucleation has been studied in an attempt to prepare model systems with narrow size distribution of nanoparticles [7]. In fact, gas phase size selected clusters and nanoparticles have been deposited in order to create monodisperse model systems [8] but so far, experimental proof that theses systems fulfill the promise is scarce [9]. In the present paper we will briefly discuss three different examples from our laboratory in order to document current progress with respect to oxidation model catalysts. The first one demonstrates how to engineer defects, such as color center, on a model $\mathrm{MgO}(100)$ surface [10] and use them as nucleation centers for Au aggregates in an attempt to calibrate circumstantial experimental evidence $[9,11]$ for charge transfer from the substrate to the Au aggregate, thought to be important in low temperature CO oxidation [12]. The second example involves oxidative methanol dehydrogenation on Pd nanoparticles in the $4 \mathrm{~mm}$ size range in order to show the influence of defects, such as edges and corners, on the selectivity of the reaction $[13,14]$. The third example discusses structure-morphology-to-spectroscopy correlations on nanoparticles

\footnotetext{
${ }^{1}$ Phone: +49-30-8413 4100, freund@fhi-berlin.mpg.de
} 
of vanadium oxide on different oxide substrates, in particular with respect to generally accepted assignments in vibrational spectroscopy [15-17].

\section{$\underline{\text { Experimental }}$}

Experiments have been carried out in a number of ultrahigh vacuum systems located at the Fritz Haber Institute in Berlin. The experimental details have been reported in the literature and we refer to these papers for a detailed description [13, 15, 18].

\section{$\underline{\text { Results and Discussion }}$}

$\mathrm{MgO}(100)$ and $\mathrm{Au} / \mathrm{MgO}(100)$ : Engineering defects

By depositing Mg in an oxygen ambient on $\mathrm{Ag}(100)$ and $\mathrm{Mo(100)}$ one may grow ordered $\operatorname{MgO}(100)$ films $[19,20]$ as imaged in Fig. 1a. The surface exposes terraces and steps and in particular terraces which correspond to regions of the film of varying thickness [21]. This allows us to study the electronic structure of the support as a function of thickness by performing scanning tunneling spectroscopy (STS) experiments. Fig. 1b shows an scanning tunneling spectrum of a MgO film [22] of 4 monolayer thickness. At this coverage one observes a band gap very similar to the bulk material, while for thinner layers variations indicating the influence of the metallic substrate are observed.

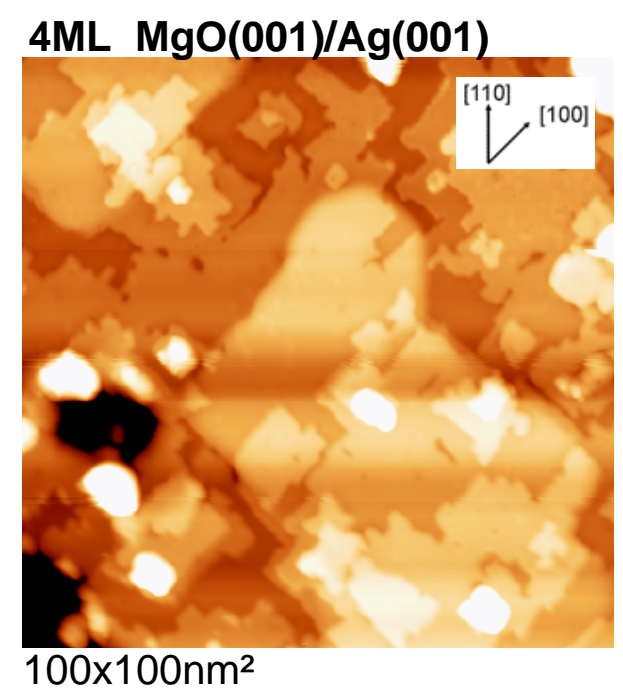

Fig. 1 (a)Scanning tunneling microscopy (STM) of an $\mathrm{MgO}(100)$ film grown on $\mathrm{Ag}(100)$ and imaged at $4 \mathrm{~K}$ 


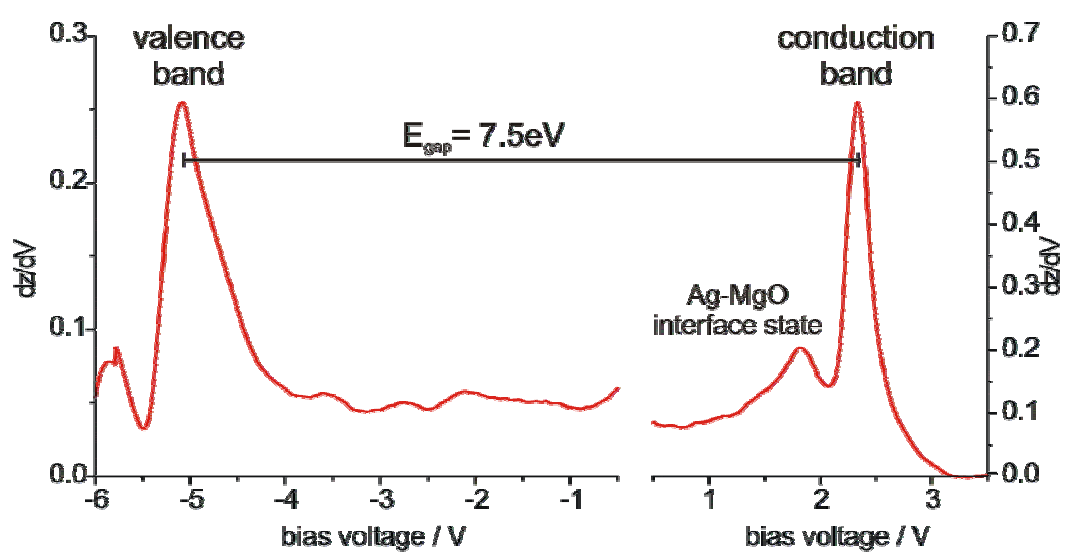

Fig. 1 (b) Scanning tunneling microscopy (STM) taken on the $\mathrm{MgO}(100) / \mathrm{Ag}(100)$ film at a spot with nominal thickness of 4 monolayers MgO.

Obviously, the film, also, exposes a considerable number of defects, including step and edge sites but the number of terrace defects, and in particular the number of oxygen vacancies (so called F centers), is very small. The absence of paramagnetic color centers has independently been proven via ESR spectroscopy on the same films [10]. Color centers, however, can be created by electron bombardment and then spectroscopically identified via STS [22] as shown in Fig. 2 or via ESR spectroscopy [10] as recently demonstrated. Correlation between experiment and theory indicates that we are dealing with two different types of color centers, in particular the neutral $F_{s}^{o}$ centers characterized by states below and above the Fermi energy, and $F_{s}^{+}$centers characterized by an occupied state whose energy depends strongly on its location at the surface, i.e. its coordination [22].
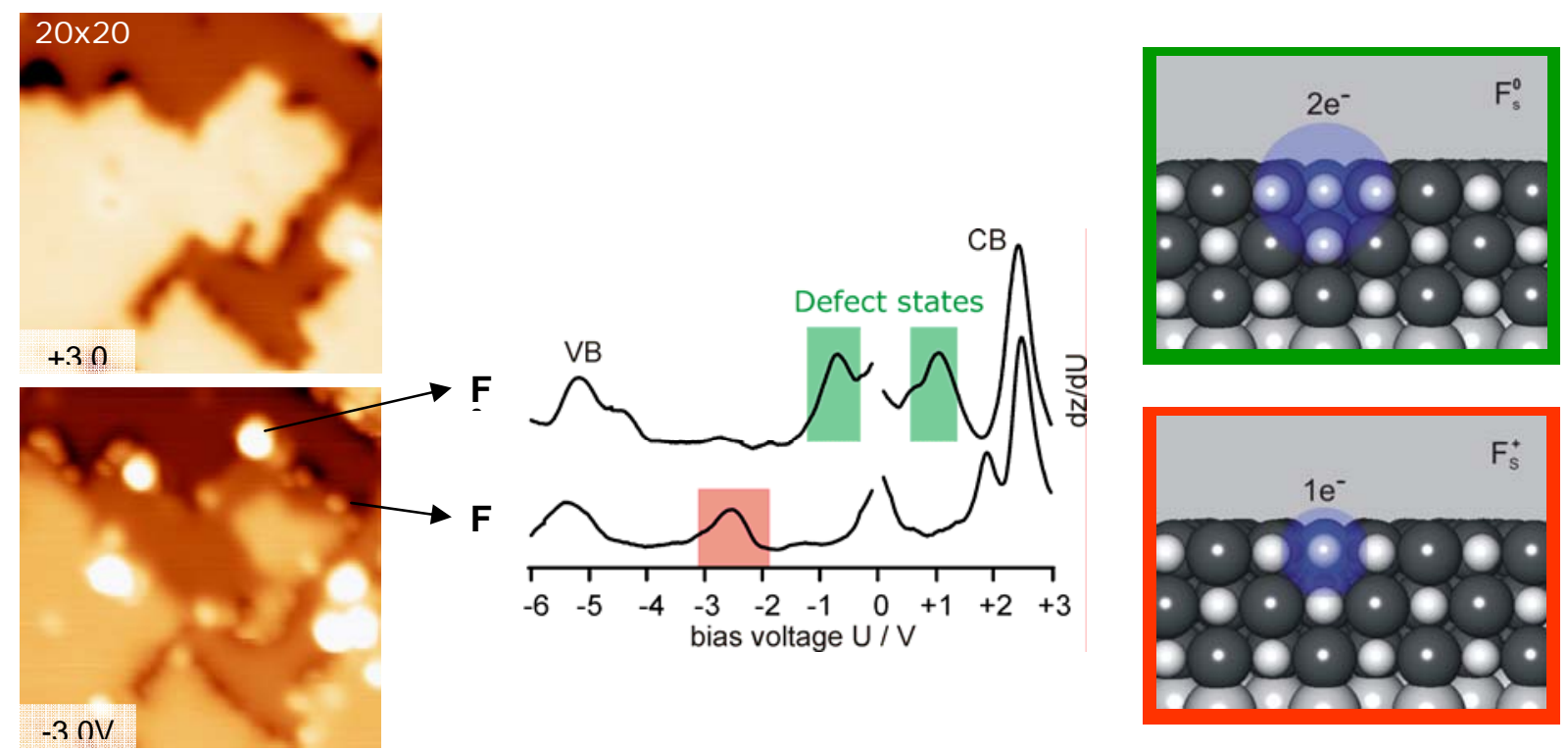
Fig. 2 STM images and STS spectra of color centers on $\mathrm{MgO}(100)$ after irradiation of the sample with electrons. On the right hand side a schematic representation of the color centers within the $\mathrm{MgO}(100)$ surface is shown.

Depositing metal atoms onto such surfaces allows us to differentiate metal aggregates located on non-defect sites and defect sites using the above information. Fig. 3 shows Au atoms and small Au clusters deposited onto a MgO surface [23]. The left panel represents Au atoms on flat MgO terraces, the middle panel images Au aggregate sitting at step sites and in the right panel one $\mathrm{Au}$ atom is localized at defects. It is possible to prepare surfaces with dominant coverage of each of the different Au adsorbates indicated in Fig. 3. This allows us to take IRAS spectra of carbon-monoxide adsorbed onto $\mathrm{Au}$ atoms and aggregates in different environments [24].
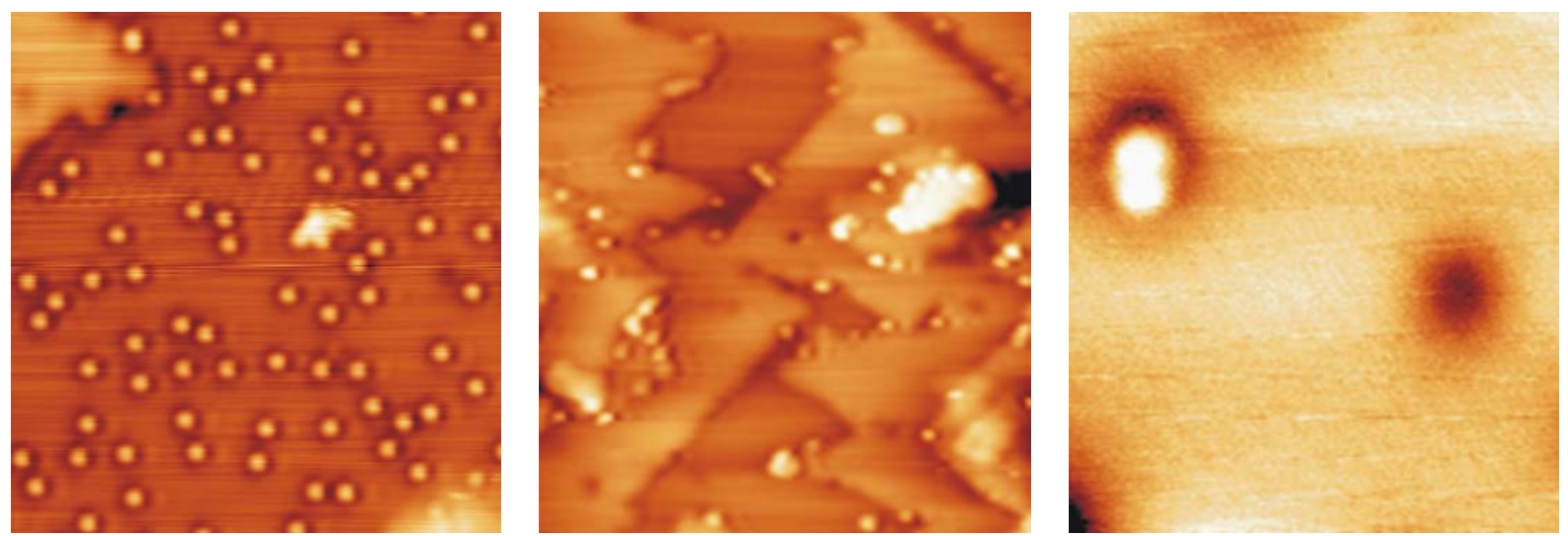

Fig. 3 Low-temperature (5K) STM images of gold atoms on $4 \mathrm{ML} \mathrm{MgO(001)/Ag(001):}$

a) Au deposition at $5 \mathrm{~K}\left(20 \times 20 \mathrm{~nm}^{2}\right)$.

b) Au deposition at $80 \mathrm{~K}\left(20 \times 20 \mathrm{~nm}^{2}\right)$.

c) Au deposition at $5 \mathrm{~K}$, nucleation on defect $\left(5 \times 5 \mathrm{~nm}^{2}\right)$.

Fig. 4a shows IRAS spectra of $\mathrm{CO} / \mathrm{Au} / \mathrm{MgO}(100)$. The left panel summarizes data for $\mathrm{Au}$ aggregates on regular terrace sites giving rise to a CO stretching frequency near $2121 \mathrm{~cm}^{-1}$ while for $\mathrm{CO}$ molecules residing on $\mathrm{Au}$ aggregates located on color centers a stretching frequency in the range of 2010 to $2080 \mathrm{~cm}^{-1}$ is observed. The characteristic width in the latter case is due to the heterogeneity of $\mathrm{Au}$ aggregates adsorbate sites. Note that the narrower intense CO stretching bands above $2150 \mathrm{~cm}^{-1}$ are due to $\mathrm{CO}$ adsorbed on $\mathrm{MgO}(100)$ as discussed recently [25, 26]. We know from calculations as well as from ESR measurements that $\mathrm{Au}$ atoms become negatively charged when adsorbed on color enters. Knowing the site of adsorption and the IRAS spectra we are in a position to calibrate the accumulated evidence on CO stretching vibrations on Au used to probe and characterize real Au catalyst samples. Fig. $4 \mathrm{~b}$ shows a schematic representation of observed CO stretching frequencies together with the assignment proposed in the literature [27]. If we include the data discussed above it is clear 
that the assignment proposed in the literature is correct but on the basis of the present study the literature data may be calibrated for the first time.

a)

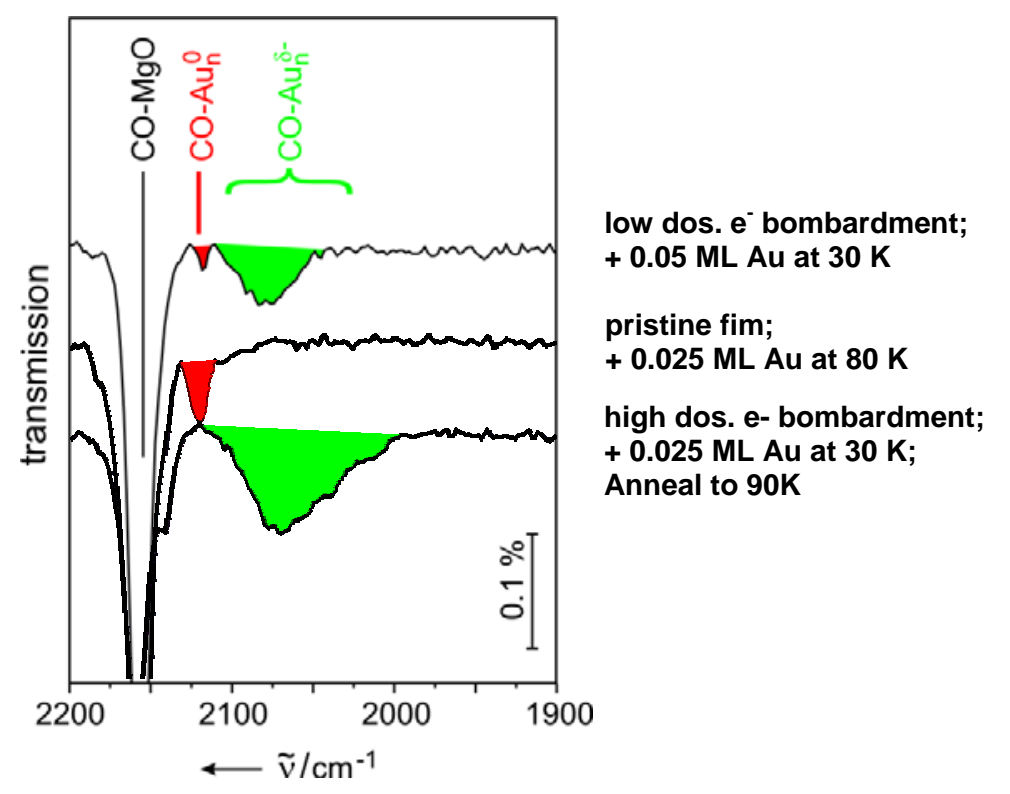

b)

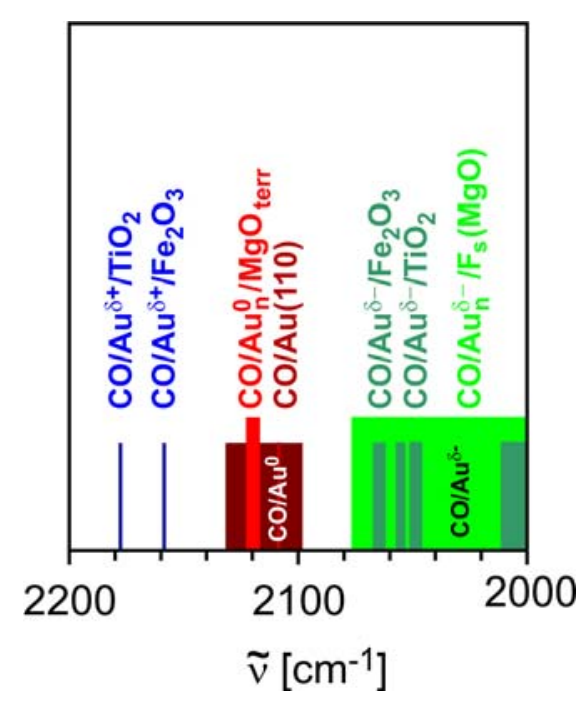

Fig. 4 (a) IR spectra of $1 \mathrm{~L}$ CO adsorbed at $30 \mathrm{~K}$ on Au deposits

(b) comparison of the stretching frequencies from a with data reported in the literature for Au catalysts [27]

\section{Oxidative Methanol Dehydrogenation on Pd-Nanoparticles}

Methanol dehydrogenation, i.e. the reverse reaction of one of the most important transformation in heterogeneous catalysis, serves as a model to study selectivity $[13,14]$. Here we consider the formation of $\mathrm{CO}$ (or $\mathrm{CO}_{2}$ in the presence of oxygen) in competition with the splitting of the carbon-oxygen bond and the formation of deposited carbon. A carbonmonoxide titration experiment as shown in Fig. 5 indicates that the $\mathrm{C}-\mathrm{O}$ bond cleavage actually occurs initially on the edges and the small (100) facets of the truncated Pd cubooctahedra that grow on a thin alumina film on top of a $\mathrm{NiAl}(110)$ single crystal, while the dehydrogenation reaction happens on the $\operatorname{Pd}(111)$ facets of the nanoparticles $[13,14]$. 


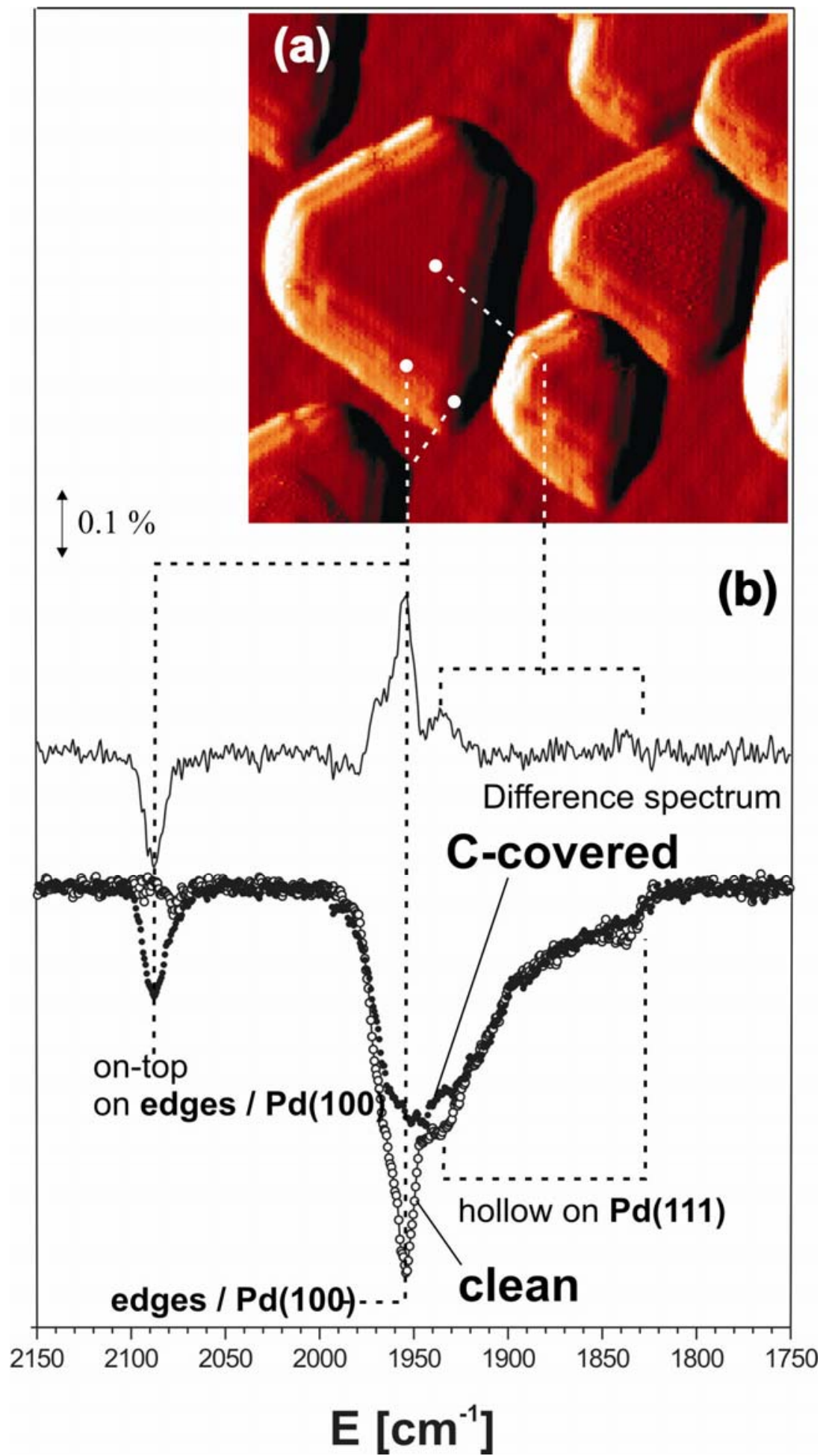

Fig. 5 (a) STM image of the Pd particles grown at $300 \mathrm{~K}$ on $\mathrm{Al}_{2} \mathrm{O}_{3} / \mathrm{NiAl}(110)(20 \times 20$ $\mathrm{nm})$.

(b) RAIR spectra for $\mathrm{CO}$ adsorbed on $\mathrm{Pd} / \mathrm{Al}_{2} \mathrm{O}_{3} / \mathrm{NiAl}(110)$ taken at a sample temperature of $100 \mathrm{~K}$ after $\mathrm{CO}$ exposure at $300 \mathrm{~K}(\sim 20 \mathrm{~L})$. Open symbols: immediately after preparation; solid symbols: after extended exposure to methanol at $440 \mathrm{~K}(7000 \mathrm{~L})$; solid line: difference spectrum for the two situations.

Briefly, the IRAS spectra of adsorbed CO in the range of the CO stretching vibrations have been taken on the freshly prepared particles before reaction has taken place (white data 
points) and after the particles have undergone reaction (black data points). There are obvious differences. Indeed, particular sites, i.e. those associated with edge sites and the (100) facets of the particles are blocked after chemical reaction. Note that the appearance of the CO stretching signal in the range of on top linearly bonded CO is connected with a difference in coverage which favors the population of on top sites (which would also occur on the freshly prepared particles). The results can be taken as an indication that the sites which are blocked, as indicated by the $\mathrm{CO}$ titration experiments, are the reactive sites for $\mathrm{C}-\mathrm{O}$ bond coverage which, in turn, are involved in the deposition of carbon atoms at those sites. However, one could argue that the carbon may not be created at those sites but rather migrates to the edges in the course of the reaction. In order to investigate this aspect further, kinetic measurements, using a sophisticated molecular beam apparatus, described in detail elsewhere [3, 28], have been performed. These experiments allowed us to clearly demonstrate $[13,14]$ that in the early stages of reaction the kinetics for methanol dehydrogenation are basically independent of whether the particles are free of carbon or carbon decorated, indicating that the C-O bond cleavage that leads to carbon deposition, indeed, occurs on the edges, corners and (100) facets of the Pd nanoparticles, while methanol dehydrogenation occurs at early stages on the (111) facets.

\section{Oxygen storage in Pd nanoparticles on $\mathrm{Fe}_{3} \mathrm{O}_{4}(111)$}

In oxidation reactions the fate of oxygen interacting with deposited metal particles is an interesting problem. With the following case study we show that the interface between the metal nanoparticle and the support plays a very important role in oxygen storage and release [29]. The experiments were performed in a molecular beam apparatus where Pd nanoparticles of various sizes were grown on a $\mathrm{Fe}_{3} \mathrm{O}_{4}(111)$ substrate. In a previous study it had been shown that smooth $\mathrm{Fe}_{3} \mathrm{O}_{4}$ (111) films can be grown on a $\mathrm{Pt}(111)$ single crystal surface [30]. The $\mathrm{Pd}$ particles were exposed to a given oxygen dose at three different temperatures $(300,400,600$ $\mathrm{K}$ ) and, subsequently, the oxygen was titrated off with varying doses of CO from a second beam. The integrated signal of the desorbing $\mathrm{CO}_{2}$ represents a quantitative measure of the oxygen stored [3]. In Fig. 6 the result of such experiments are shown. It is obvious that the oxygen adsorbed at low temperature $(300 \mathrm{~K})$ is titrated off within the first few pulses whereas it takes an order of magnitude higher dosage to oxidize the carbonmonoxide after the particles have been exposed to oxygen at higher temperature (600 K). 


\section{Pd Oxide Formation: CO Titration on pre-oxidized Pd Particles}

\section{$\mathrm{CO}_{2}$ Yield Per Puls}

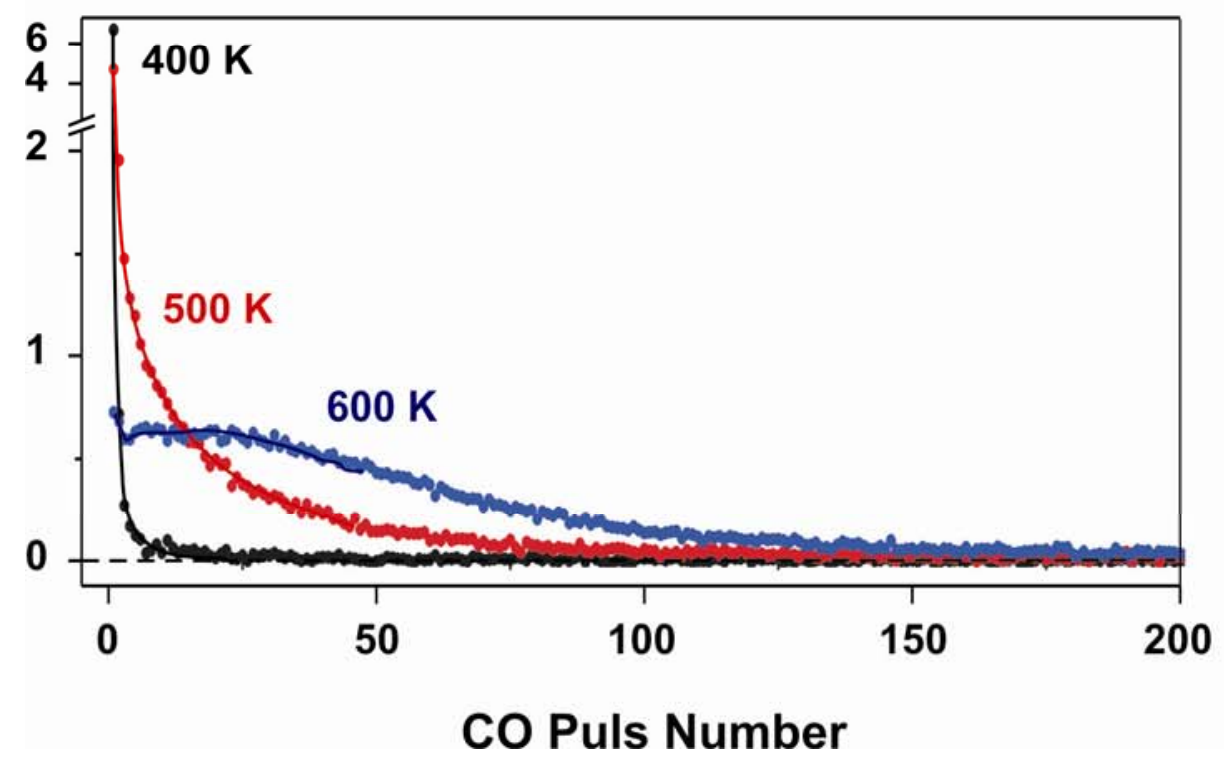

Total $\mathrm{CO}_{2}$ Yield

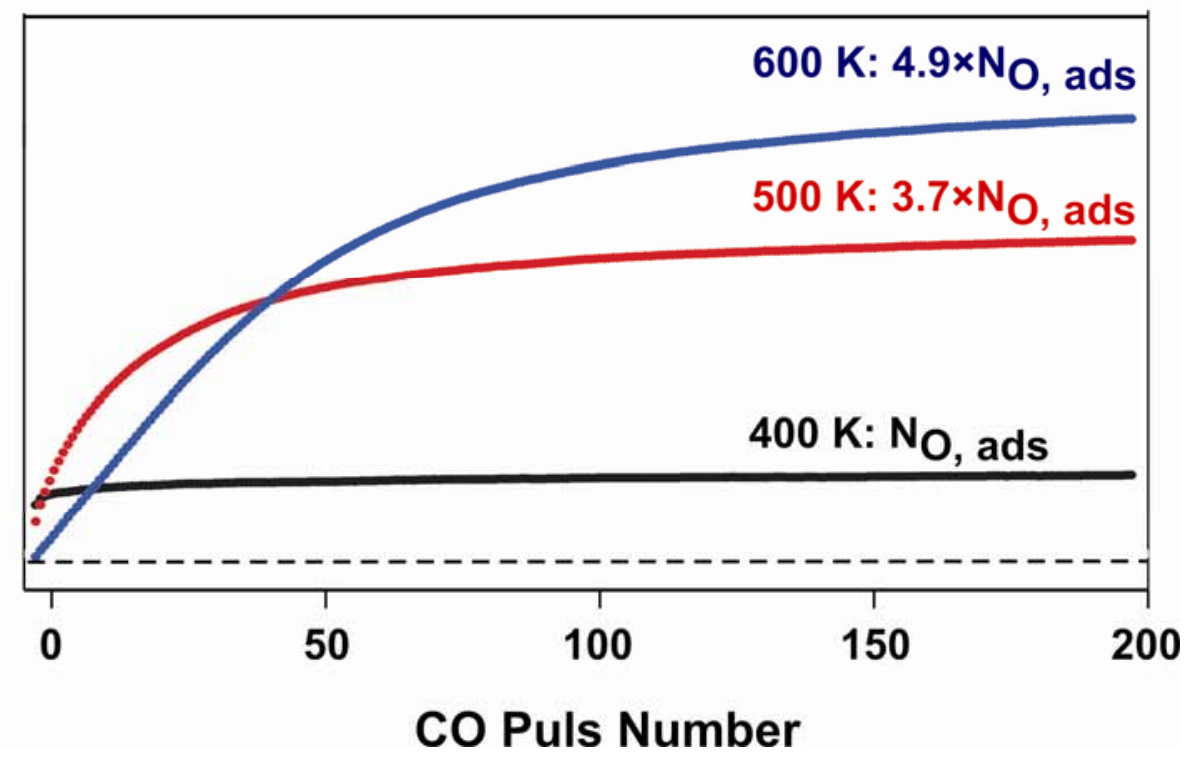

Fig. 6 Pulsed $\mathrm{CO}$ titration experiment on the $\mathrm{Pd} / \mathrm{Fe}_{3} \mathrm{O}_{4}$ model catalyst after oxygen exposure at different sample temperatures. Initially the model surface is exposed to a pulse of ${ }^{18} \mathrm{O}_{2}(100 \mathrm{~s}, 130 \mathrm{~L})$. After a delay time $(10 \mathrm{~s})$, pulses of CO (on-time $5 \mathrm{~s}$, off-time $5 \mathrm{~s}$ ) are applied to remove oxygen stored on the catalyst surface in form of $\mathrm{CO}_{2}$ : (a) $\mathrm{CO}_{2}$ yield per $\mathrm{CO}$ pulse; (b) total $\mathrm{CO}_{2}$ yield. 
The release of oxygen is also delayed. The reason is clear: At low temperature oxygen exposure leads to the formation of chemisorbed oxygen only, which oxidizes CO immediately to from $\mathrm{CO}_{2}$. At higher temperature oxygen exposure may lead to the formation of $\mathrm{PdO}_{\mathrm{x}}$ species within the particle surface or within the particle which is only slowly released to form $\mathrm{CO}_{2}$. The question arises where in the particle the oxygen is stored [29]. In order to address this question, photoelectron $\mathrm{Pd}_{3 / 2}$ spectra have been taken for the different photon energies (see Fig. 7). At $465 \mathrm{eV}$ photon energy the electrons carry a kinetic energy near $150 \mathrm{eV}$, and are characterized by a very small escape depth. At $840 \mathrm{eV}$ photon energy the kinetic energy is such that the entire particles including the interface to the $\mathrm{Fe}_{3} \mathrm{O}_{4}(111)$ substrate are probed. Fig. 7a (top panel) shows, on the left, the assignment of spectral features for the clean and, on the right, for the particles oxidized at $600 \mathrm{~K}$, taken at $450 \mathrm{eV}$ photon energy. The bottom panel shows the equivalent data recorded at $840 \mathrm{eV}$ photon energy. 


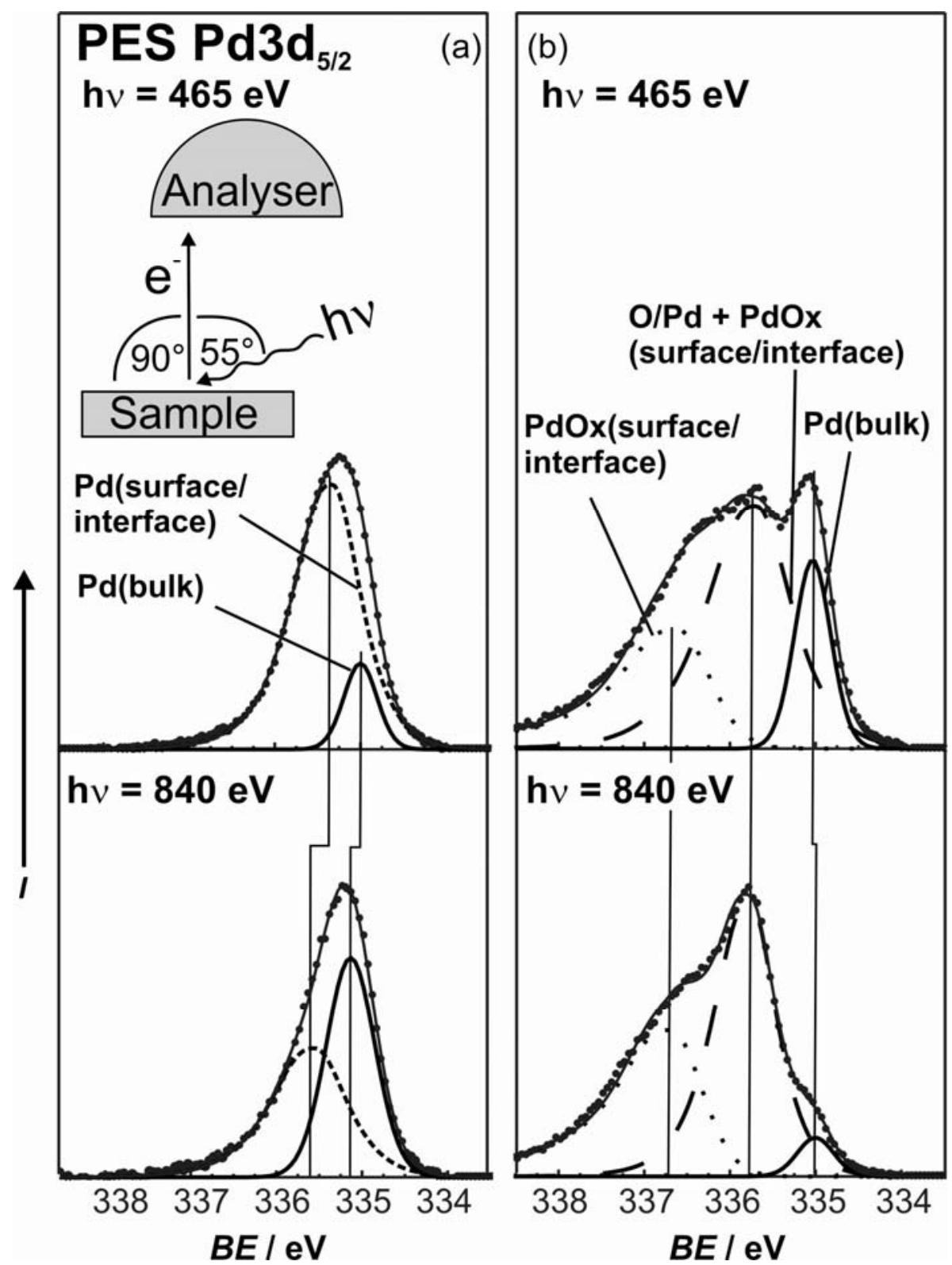

Fig. 7 High resolution core level spectra of $P d 3 d_{5 / 2}$ region after preparation of the model catalyst at different photon energies: (a) immediately after Pd deposition and annealing in UHV to $600 \mathrm{~K}$; (b) after oxygen exposure at $600 \mathrm{~K}$ (oxygen dose: $800 \mathrm{~L}$ ).

For the clean particles the change in line shape can be explained on the basis of literature data $[31,32]$ as to be due to a dominance of the surface Pd peak chemically shifted against the "bulk" peak for low escape depth, and the dominance of the bulk feature for larger escape depth. For the particles exposed to oxygen a broad $\mathrm{PdO}_{\mathrm{x}}$ feature is found at higher binding energies and may also be basically assigned on the basis of literature data [29, 31, 32]: The important information is the change in the relative intensity of the Pd peak characteristic of the metal as opposed to the signals originating from the oxide. If the Pd oxide were located at or near the outer surface of the Pd particles one would have expected an increase in the metal feature with respect to the oxide feature as more of the interior of the particles is probed. The 
opposite is the case, indicating that the $\mathrm{PdO}_{\mathrm{x}}$ species is not formed at or near the gas-Pd interface but rather at the $\mathrm{Pd}$ support interface. This easily explains the observed COoxidation behavior: the interfacial $\mathrm{PdO}_{\mathrm{x}}$ is slowly released as the Pd surface is dosed with carbon-monoxide. Additional data (not shown) indicate that the formed $\mathrm{PdO}_{\mathrm{x}}$ only very slowly exchanges oxygen with the support oxide. STM data taken on the Pd particles upon heating in ultrahigh vacuum and under ambient oxygen pressure conclusively indicate that the oxygen environment leads to a restructuring, i.e. growth and crystallization of the $\mathrm{Pd}$ nanoparticles [29]. In order to support the idea of an interfacial $\mathrm{PdO}_{\mathrm{x}}$ we have performed the equivalent experiments as a function of Pd particle size [33]. The results of those experiments are summarized in Fig. 8. Here the integral amount of $\mathrm{CO}_{2}$ produced in $\mathrm{CO}$ oxidation experiments is plotted against the Pd particle size, the morphologies of which are illustrated by STM images for selected preparations at the bottom of Fig. 8. Parallel to the $\mathrm{CO}_{2}$ production we plot the CO sticking coefficient as a function of particle size which shows the expected saturation behavior as the Pd loading approaches full coverage. 


\section{Total Oxygen Storage Capacity as a Function of Particle Size}

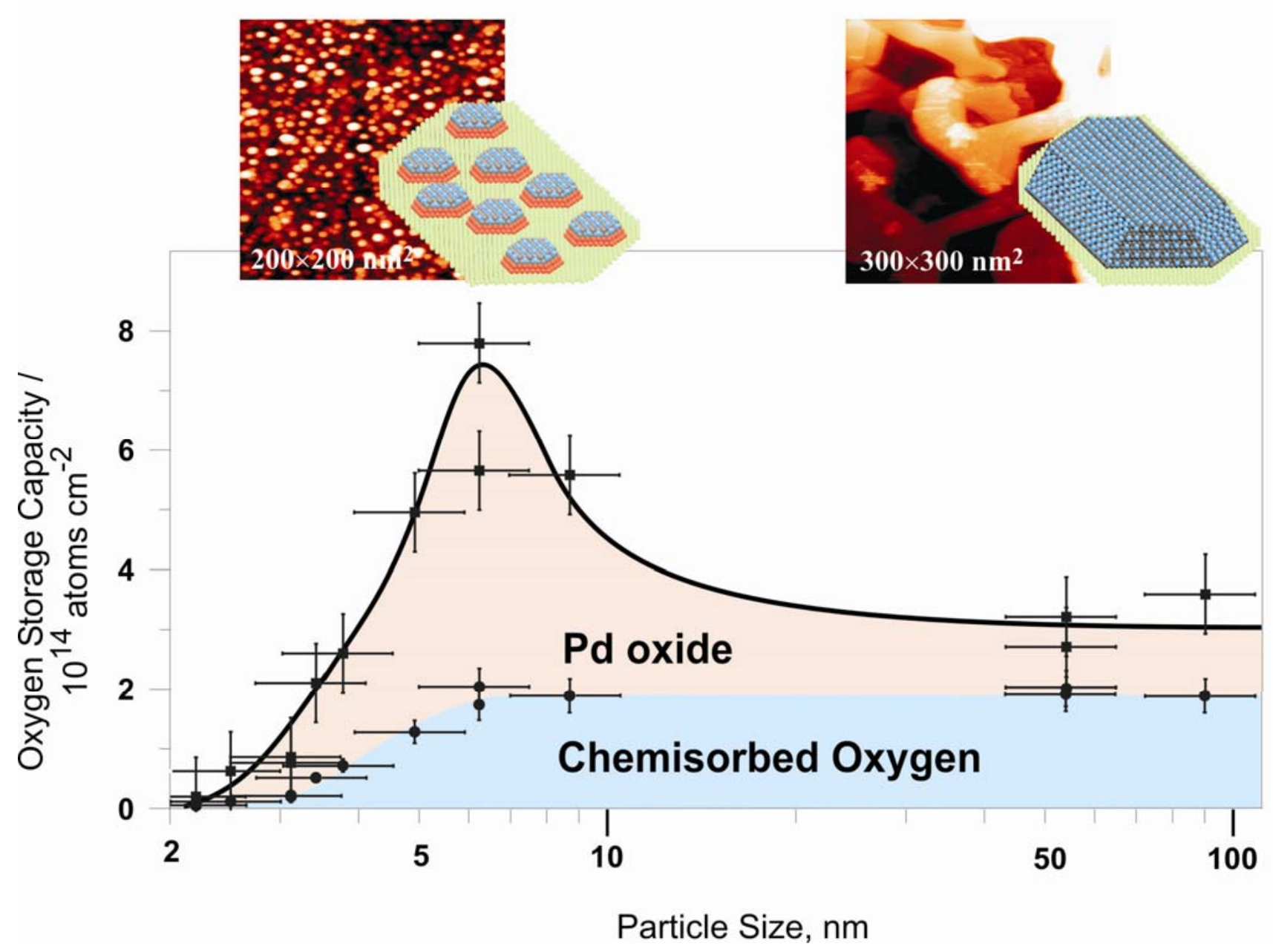

Fig. 8 Oxygen storage on a $\mathrm{Pd} / \mathrm{Fe}_{3} \mathrm{O}_{4}$ model catalyst after $130 \mathrm{~L}$ oxygen exposure at $500 \mathrm{~K}$ as a function of Pd particle size. Total oxygen storage capacity is divided into oxygen chemisorption on the metallic Pd surface (blue area, determined from a sticking coefficient measurement) and Pd interface oxide formation (red area). 
The important information is that $\mathrm{CO}_{2}$ production shows a clear maximum at an intermediate size regime. This is fully consistent with the idea that the $\mathrm{PdO}_{\mathrm{x}}$-support interfacial oxide is responsible for the observed slow CO oxidation: For smaller particles the exposed interface gradually grows and reaches a maximum because as the particles start to coalesce the exposed interface gets smaller.

We believe that the observed interfacial oxide formation is not limited to the case of $\mathrm{Pd} /$ $\mathrm{Fe}_{3} \mathrm{O}_{4}$ but may be of more general importance in oxidation reactions.

\section{Supported Vanadium Model Catalysts: Morphology-Spectroscopy Relations}

In a similar way as metal nanoparticles are formed on thin film oxide supports, transition metal oxide nanoclusters can be formed by depositing a metal in an oxygen ambient [17]. Socalled vanadium oxide monolayer catalysts have played a major role in designing new catalysts for selective oxidation reactions [34, 35]. In this case vanadium is supported on various oxides such as $\mathrm{Al}_{2} \mathrm{O}_{3}, \mathrm{SiO}_{2}, \mathrm{TiO}_{2}, \mathrm{CeO}_{2}$ and the activities and selectivities in oxidation reactions depend strongly on the chosen support. Depending on vanadium oxide loading either $\mathrm{VO}_{\mathrm{x}}$ (monomeric) species or $\mathrm{V}_{\mathrm{x}} \mathrm{O}_{\mathrm{y}}$ (polymeric) species displaying $\mathrm{V}-\mathrm{O}-\mathrm{V}$ bonds are formed. A characteristic band, specifically observed in Raman spectra of vanadia on alumina supports around $950 \mathrm{~cm}^{-1}$, as opposed to the absence of this band on silica, has been interpreted as being due to the formation of polymeric species early on in the catalyst formation for alumina supported vanadium oxide catalysts [34-36]. We have shown in a recent model study [17], combining experimental and theoretical results that this interpretation needs to be reconsidered. In the following we briefly summarize the results of this study.

Fig. 9 shows STM images of $\mathrm{VO}_{\mathrm{x}}$ nanoparticles on alumina and silica model supports. The top panel show high coverage situations and it is clear from the granular morphology observed that these model systems cannot really be called monolayer catalysts. The bottom panel shows low coverage model systems of $\mathrm{VO}_{\mathrm{x}}$ on silica. The $\mathrm{SiO}_{2}$ network can be seen at atomic resolution and individual $\mathrm{VO}_{\mathrm{x}}$ moieties may be imaged down to a size that likely represent $\mathrm{VO}_{4}$ units as judged by the sizes in the image, based on the knowledge of the atomic distances in the silica support [37]. 


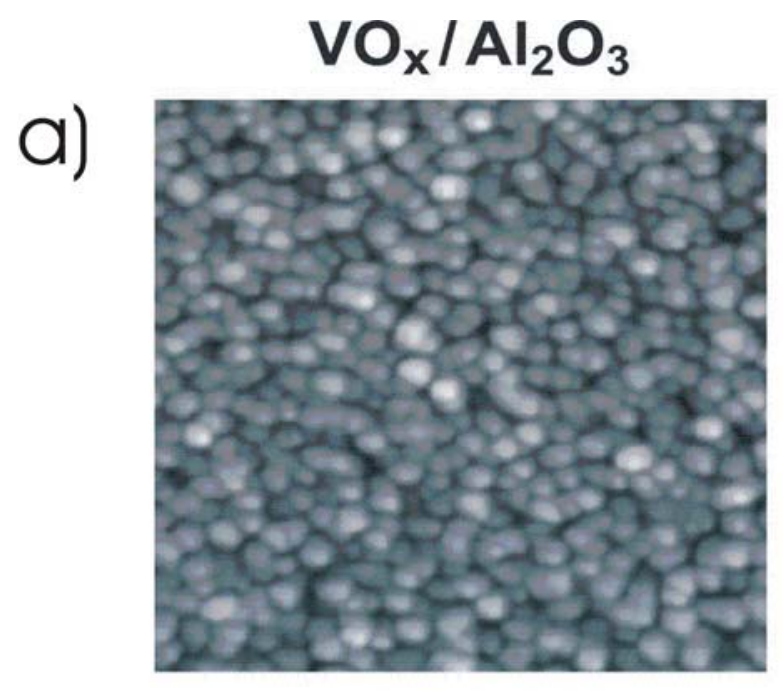

$0.32 \mathrm{MLV}$
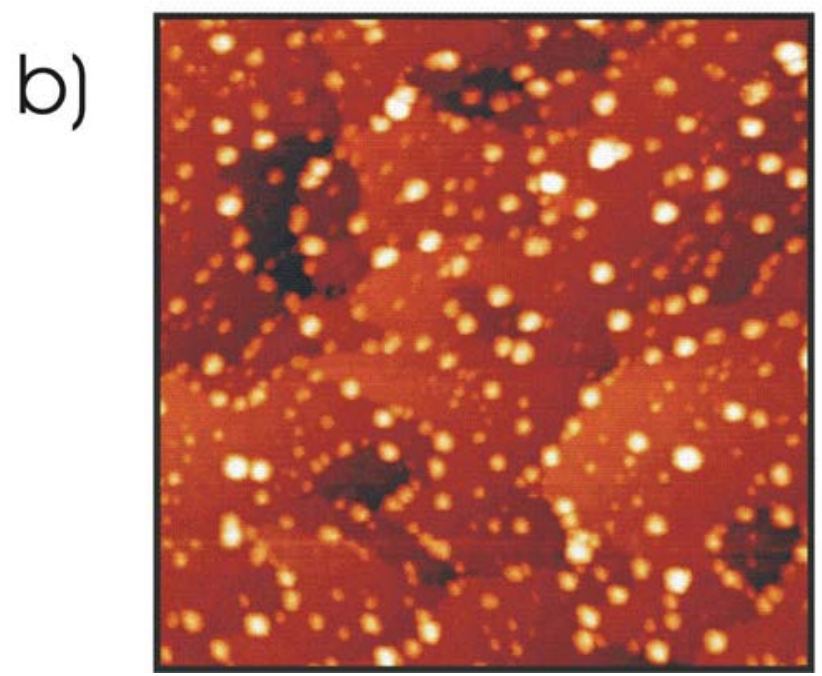

$\mathrm{VO}_{\mathrm{x}} / \mathrm{SiO}_{2}$

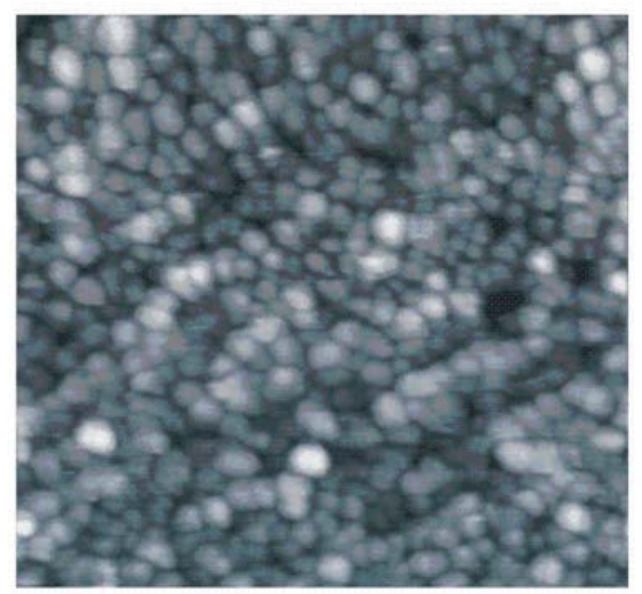

$0.4 \mathrm{MLV}$

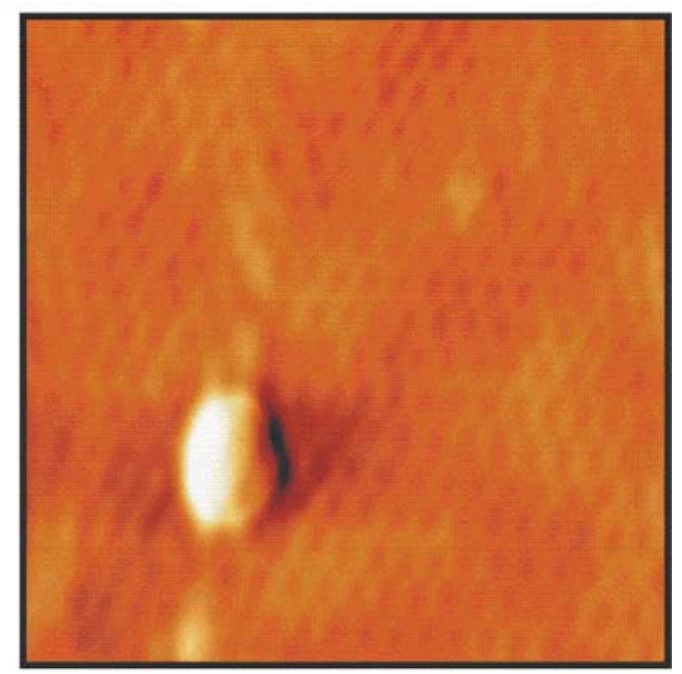

Fig. 9: a) Comparison of two STM images ( $50 \mathrm{~nm} \times 50 \mathrm{~nm}$ ) measured for alumina- and silica-supported vanadia particles of similar $\mathrm{V}$-content. Tunneling was performed at the following conditions: $\mathrm{U}=2.2 \mathrm{~V}, \mathrm{I}=0.07 \mathrm{nA}\left(\mathrm{VO}_{\mathrm{x}} / \mathrm{Al}_{2} \mathrm{O}_{3}\right) ; \mathrm{U}=3.3$ $\mathrm{V}, \mathrm{I}=0.12 \mathrm{nA}\left(\mathrm{VO}_{\mathrm{x}} / \mathrm{SiO}_{2}\right)$. In both cases, particle number densities between $\sim 1.8$ $1.9 \times 10^{13}$ particles per $\mathrm{cm}^{-2}$ were determined.

b) STM images of $\mathrm{VO}_{\mathrm{x}} / \mathrm{SiO}_{2}$ at lower $\mathrm{VO}_{\mathrm{x}}$ coverage. The right panel shows a single $\mathrm{VO}_{\mathrm{x}}$ cluster on the atomically resolved $\mathrm{SiO}_{2}$ substrate.

Fig. 10 contains the corresponding vibrational spectra recorded with IRAS spectroscopy. This spectroscopic method is very efficient due to the metallic singly crystal used to grow the alumina and silica supports. 

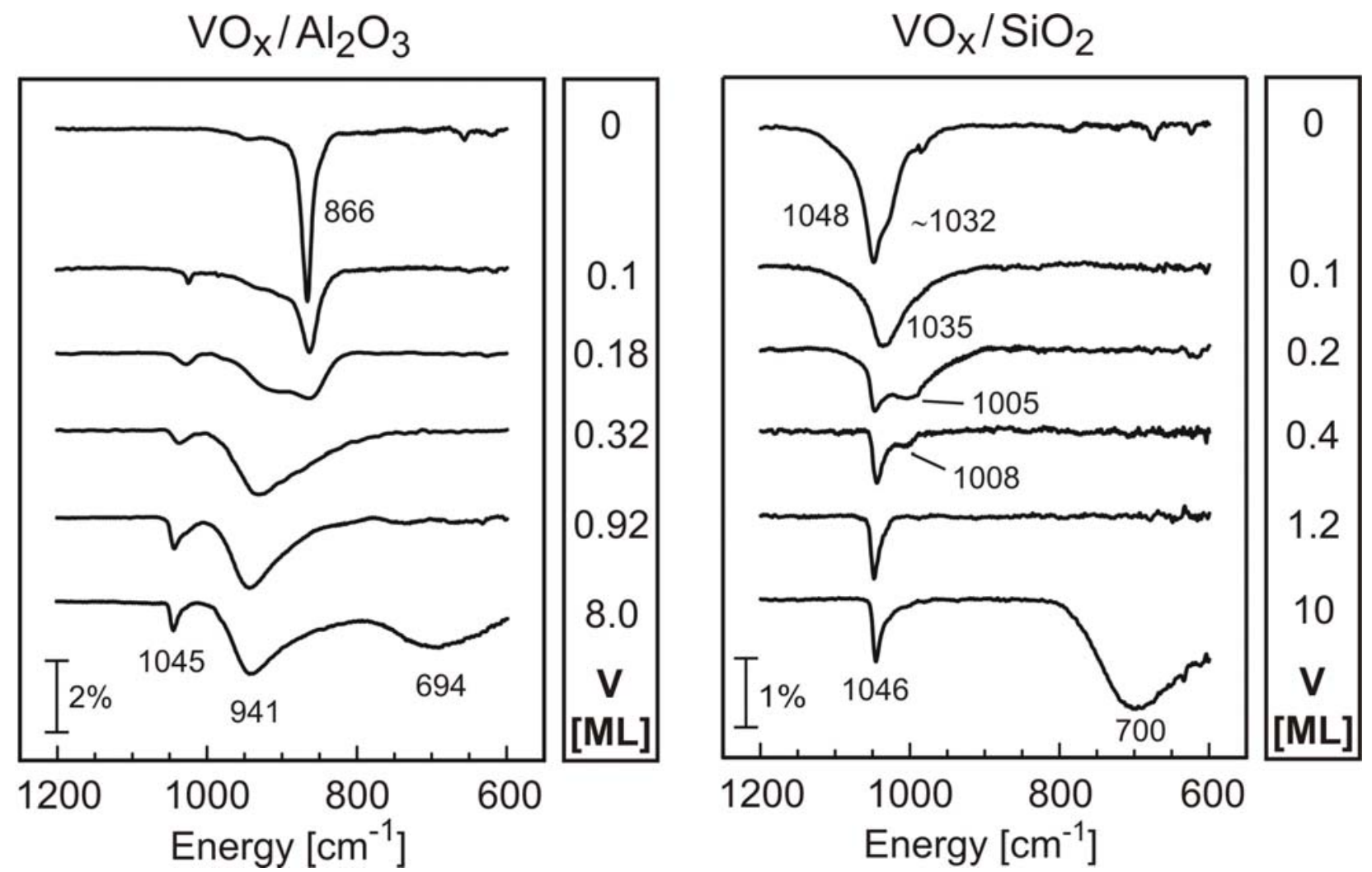

Fig. 10 IR spectra from alumina- and silica-supported vanadia particles as a function of $\mathrm{V}$-coverage. All spectra were measured at $300 \mathrm{~K}$ and referenced to the underlying $\mathrm{NiAl}$ and Mo metal substrates, respectively.

Spectra are shown for coverages ranging from low to high loading. A characteristic band near $1058 \mathrm{~cm}^{-1}$ occurs for both supports, changing its frequency as the coverage is increased. While in the case of alumina this band retains its rather simple line shape, the corresponding band for silica supported vanadia undergoes rather complex changes in line shape until its habit becomes similar to the alumina case for higher coverages. The literature assigns this single band to $\mathrm{V}=\mathrm{O}$ double bonds involved in the formation of $\mathrm{O}=\mathrm{VO}_{3}$ tetrahedra [35, 38]. For the case of vanadium oxide deposits on alumina a band near $950 \mathrm{~cm}^{-1}$ grows in at intermediate coverage and persists to high coverage. This is the band addressed above, which is absent for vanadium oxides on silica supports. Both supported $\mathrm{VO}_{\mathrm{x}}$ systems, however, show a band around $700 \mathrm{~cm}^{-1}$ which would have to be assigned to $\mathrm{V}-\mathrm{O}-\mathrm{V}$ phonons known for vanadium sesqui oxide $\left(\mathrm{V}_{2} \mathrm{O}_{3}\right)$ solid samples [17]. The group of J. Sauer at the HumboldtUniversität zu Berlin has performed model calculations [16, 17] that allow us now to consistently assign both sets of spectra. Typical cluster models used in the calculation are depicted in Fig. 11 together with the range of frequencies for the vanadyl vibrations, the V-Ointerfacial modes and the V-O-V modes. 

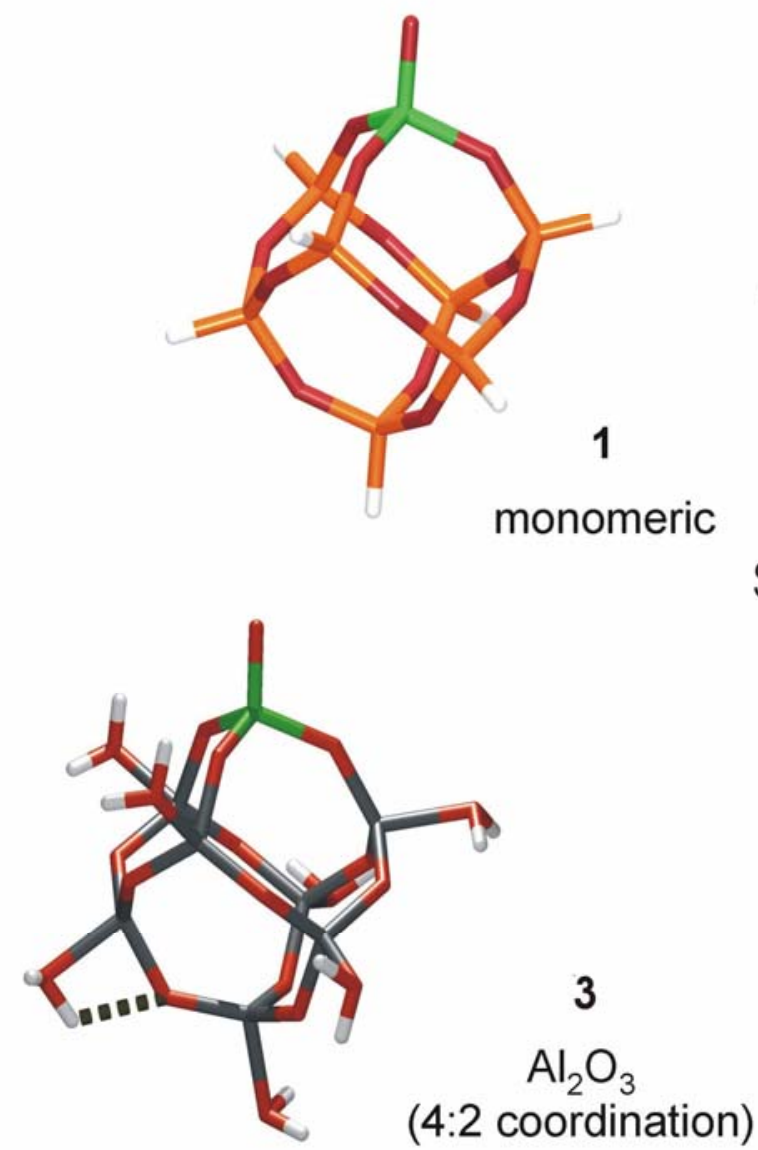

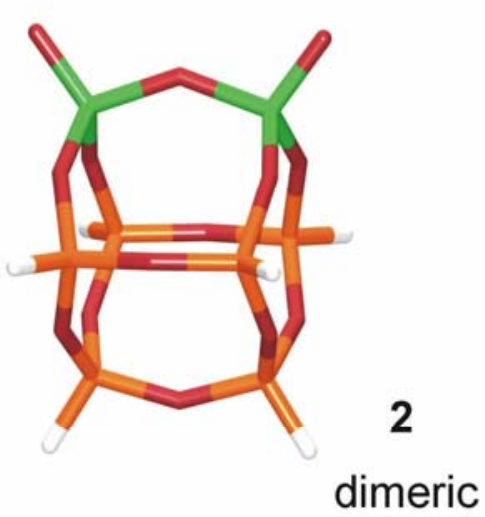

$\mathrm{SiO}_{2}$

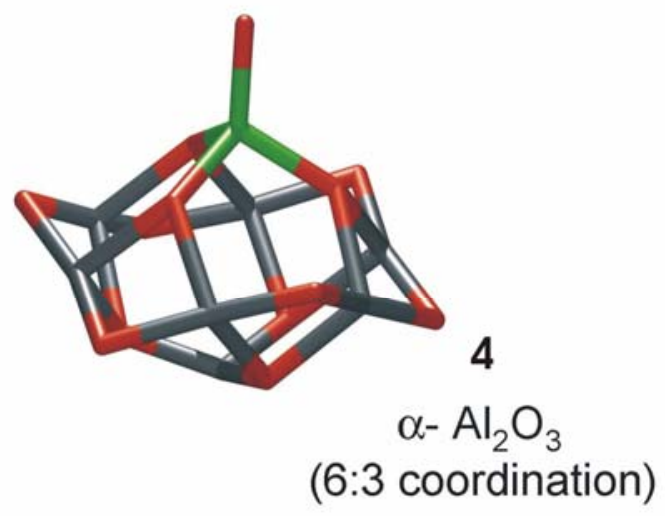

$$
V=0 \underset{\text { in-phase out-of-phase }}{V-O}
$$

Silica supported $\mathrm{V}_{2} \mathrm{O}_{5}$, monomeric

(1)

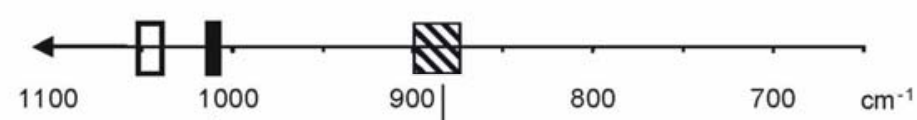

Silica supported $\mathrm{V}_{2} \mathrm{O}_{5}$, dimeric

(2)

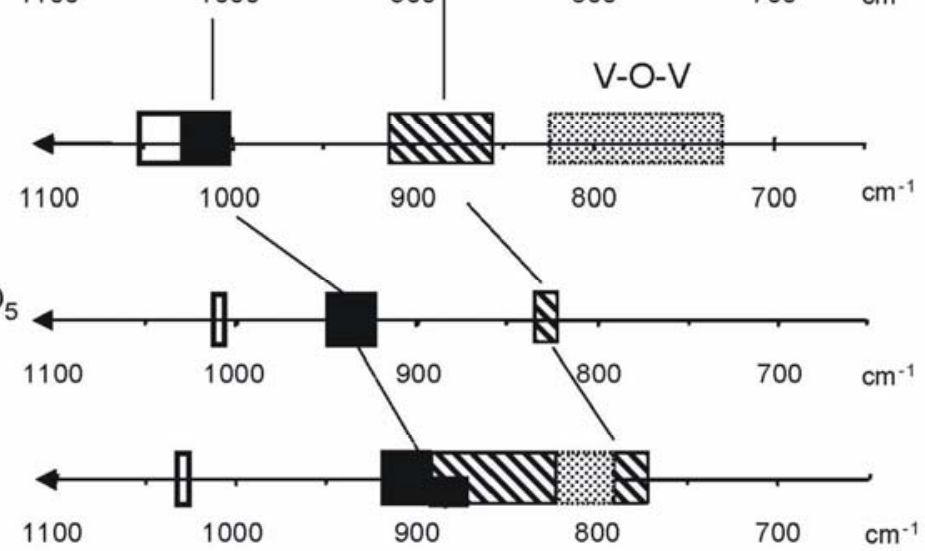

(4)

(4:2)-alumina supported $\mathrm{V}_{2} \mathrm{O}_{5}$

$\alpha$-alumina supported $\mathrm{V}_{2} \mathrm{O}_{5}$ dimeric

Fig. 11 Models for silica supported vanadium oxide. Frequency ranges for V-O stretching vibrations of models for different species and different supporting oxides. 
On the basis of this figure it is clear that the band near $1050 \mathrm{~cm}^{-1}$ is due to the $\mathrm{V}=\mathrm{O}$ vibration and the broad band centered near $700 \mathrm{~cm}^{-1}$ is due to $\mathrm{V}-\mathrm{O}-\mathrm{V}$ vibrations. The interface vibrations behave rather differently for the two supports. While for alumina the interfacial modes are well separated from the vanadyl vibrations so that we can safely assign the band near $950 \mathrm{~cm}-1$ in the spectra to such interfacial V-O-Al modes, those modes (i.e. V-O-Si modes) are in close proximity of the vanadyl modes in the case of silica support. This gives rise to coupling phenomena that lead to a rather complex line shape for small coverages without exhibiting a pronounced interfacial band as in the case of the alumina supports.

In summary, we provide a consistent assignment of the observed spectral features which is at variance with the generally accepted interpretation within the catalytic literature.

\section{$\underline{\text { Synopsis }}$}

With this review of a few case studies in the investigation of model system, we have tried to summarize the state of the art in these areas. It is shown that considerable progress has been made to describe this system at the atomic level and that in some cases this information may every carry some value for understanding real catalysis.

\section{$\underline{\text { Acknowledgement }}$}

I am grateful to a number of funding agencies including German Science Foundation (DFG), Fonds der Chemischen Industrie and the European Union (IDECAT) which have contributed to the results presented here.

In particular I am indebted to my collaborators who have done most of the work, and who are mentioned in the references. 


\section{References:}

[1] C.T. Campbell, Surf. Sci. Rep., 27 (1997) 1.

[2] C.R. Henry, Surf. Sci. Rep., 31 (1998) 231.

[3] J. Libuda and H.-J. Freund, Surf. Sci. Rep., 57 (2005) 157.

[4] G. Ertl and H.-J. Freund, Physics Today, 52 (1999) 32.

[5] H.-J. Freund, M. Bäumer and H. Kuhlenbeck, Adv. Catal., 45 (2000) 333.

[6] H.-J. Freund, Surf. Sci., 500 (2002) 271.

[7] M. Bäumer and H.-J. Freund, Progr. Surf. Sci., 61 (1999) 127.

[8] U. Heiz, A. Sanchez, S. Abbet and W.-D. Schneider, J. Am. Chem. Soc., 121 (1999) 3214.

[9] B. Yoon, H. Häkkinen, U. Landman, A. Wörz, J.-M. Antonietti, S. Abbet, K. Judai and U. Heiz, Science, 307 (2005) 403.

[10] M. Sterrer, E. Fischbach, T. Risse and H.-J. Freund, Phys. Rev. Lett., 94 (2005) 186101.

[11] D. Meier and D.W. Goodman, J. Am. Chem. Soc., 126 (2004) 1892.

[12] M. Haruta, Catal. Today, 36 (1997) 153.

[13] S. Schauermann, J. Hoffmann, V. Johanek, J. Hartmann, J. Libuda and H.-J. Freund, Angew. Chem. Int. Ed., 41 (2002) 2532.

[14] S. Schauermann, J. Hoffmann, V. Johanek, J. Hartmann, J. Libuda and H.-J. Freund, Catal. Lett., 84 (2002) 209.

[15] N. Magg, J.B. Giorgi, T. Schroeder, M. Bäumer and H.-J. Freund, J. Phys.Chem. B, 106 (2002) 8756.

[16] N. Magg, B. Immaraporn, J. Giorgi, T. Schroeder, M. Bäumer, J. Döbler, Z. Wu, E. Kondratenko, M. Cherian, M. Baerns, P.C. Stair, J. Sauer and H.-J. Freund, J. Catal., 226 (2004) 88.

[17] S. Guimond, M. Abu Haija, S. Kaya, J. Weissenrieder, S. Shaikhutdinov, H.

Kuhlenbeck, H.-J. Freund and J. Sauer, Top. in Catal., accepted (2005).

[18] H.-P. Rust, M. Doering, J.I. Pascual, T.P. Pearl and P.S. Weiss, Rev. Sci. Inst., 72 (2001) 4393.

[19] J. Wollschlager, J. Viernow, C. Tegenkamp, D. Erdos, K.M. Schroder and H. Pfnur, Appl. Surf. Sci., 142 (1999) 129.

[20] M.-C. Wu, J.S. Corneille, C.A. Estrada, J.-W. He and D. Wayne Goodman, Chem. Phys. Lett., 182 (1991) 472.

[21] S. Schintke, S. Messerli, M. Pivetta, F. Patthey, L. Libioulle, M. Stengel, A. De Vita and W.-D. Schneider, Phys. Rev. Lett., 87 (2001) 276801.

[22] M. Sterrer, M. Nowicki, M. Heyde, N. Nilius, T. Risse, H.-P. Rust, G. Pacchioni and H.-J. Freund, J. Phys. Chem. B (Lett.), accepted (2005).

[23] M. Yulikov, M. Sterrer, M. Heyde, H.-P. Rust, T. Risse, H.J. Freund, G. Pacchioni and A. Scagnelli, Phys. Rev. Lett., submitted (2005).

[24] M. Sterrer, M. Yulikov, E. Fischbach, M. Heyde, H.-P. Rust, N. Nilius, G. Pacchioni, T. Risse and H.-J. Freund, Angew. Chem., submitted (2005).

[25] M. Sterrer, T. Risse and H.-J. Freund, Surf. Sci., 596 (2005) 222.

[26] M. Sterrer, T. Risse and H.-J. Freund, Appl. Catal. A, submitted (2005).

[27] R. Meyer, C. Lemire, S. Shaikhutdinov and H.-J. Freund, Gold Bulletin, 37 (2004) 72.

[28] J. Libuda, I. Meusel, J. Hartmann and H.-J. Freund, Rev. Sci. Instrum., 71 (2000)

4395.

[29] T. Schalow, M. Laurin, B. Brandt, S. Schauermann, S. Guimond, H. Kuhlenbeck, D.E. Starr, S. Shaikhutdinov, J. Libuda and H.-J. Freund, Angew. Chem. Int. Ed., 44 (2005) 7601.

[30] W. Weiss, Surf. Sci., 377-379 (1997) 943. 
[31] E. Lundgren, G. Kresse, C. Klein, M. Borg, J.N. Andersen, M.D. Santis, Y. Gauthier, C. Konvicka, M. Schmid and P. Varga, Phys. Rev. Lett., 88 (2002) 246103.

[32] M. Todorova, E. Lundgren, V. Blum, A. Mikkelsen, S. Gray, J. Gustafson, M. Borg, J. Rogal, K. Reuter, J.N. Andersen and M. Scheffler, Surf. Sci., 541 (2003) 101.

[33] T. Schalow, B. Brandt, D.E. Starr, M. Laurin, S. Shaikhutdinov, S. Schauermann and H.-J. Freund, Angew. Chem. Int. Ed., submitted (2005).

[34] G. Deo, I.E. Wachs and J. Haber, Crit. Rev. Surf. Chem., 4 (1994) 141.

[35] I.E. Wachs, Catal. Today, 100 (2005) 79.

[36] A. Khodakov, B. Olthof, A.T. Bell and E. Iglesia, J. Catal., 118 (1999) 205.

[37] J. Weissenrieder, S. Kaya, J.-L. Lu, H.-J. Gao, S. Shaikhutdinov, H.-J. Freund, M.

Sierka, T.K. Todorova and J. Sauer, Phys. Rev. Lett., 95 (2005) 076103.

[38] I.E. Wachs, Catal. Today, 27 (1996) 437. 